This item was submitted to Loughborough's Research Repository by the author.

Items in Figshare are protected by copyright, with all rights reserved, unless otherwise indicated.

\title{
Typologies of dual career in sport: a cluster analysis of identity and self- efficacy
}

PLEASE CITE THE PUBLISHED VERSION

https://doi.org/10.1080/02640414.2020.1835238

PUBLISHER

Taylor \& Francis

VERSION

AM (Accepted Manuscript)

\section{PUBLISHER STATEMENT}

This is an Accepted Manuscript of an article published by Taylor \& Francis in Journal of Sports Sciences on 15 Oct 2020, available online: http://www.tandfonline.com/10.1080/02640414.2020.1835238.

\section{LICENCE}

CC BY-NC-ND 4.0

\section{REPOSITORY RECORD}

Cartigny, Emily, David Fletcher, Christine Coupland, and Stephan Bandelow. 2020. "Typologies of Dual Career in Sport: A Cluster Analysis of Identity and Self-efficacy". Loughborough University. https://hdl.handle.net/2134/14223995.v1. 
3
Typologies of dual career in sport: A cluster analysis of identity and self-efficacy Emily Cartigny, David Fletcher and Christine Coupland Loughborough University Stephan Bandelow St George's University

Emily Cartigny, School of Sport, Exercise and Health Sciences, Loughborough

9 University, United Kingdom; David Fletcher, School of Sport, Exercise and Health Sciences, 20 Loughborough University, United Kingdom; Christine Coupland, School of Business and 1 Economics, Loughborough University, United Kingdom; Stephan Bandelow, St George’s 22 University, University Centre, Grenada, West Indies.

3 Correspondence concerning this article should be addressed to Emily Cartigny, 24 School of Sport, Exercise and Health Sciences, Loughborough University, United Kingdom. 5 E-mail: e.deason2@,1boro.ac.uk 
Typologies of Dual Career in Sport: A Cluster Analysis of Identity and Self-efficacy

Abstract

Research has previously identified different approaches to a dual career (i.e., the

5 simultaneous development of a vocational career alongside the athletic career), (a)

6 educational/vocational pathway (i.e., a prioritisation of the vocational career), (b) a parallel

7 dual career pathway (i.e., an equal focus on athletic and vocational career), and (c) a sporting

8 pathway (i.e., a prioritisation of the athletic career). Yet, the identity and self-efficacy

9 characteristics of these profiles require further investigation. The address this, the current

10 study collected survey responses from 111 dual career athletes. The survey measured aspects

11 of career identity, athletic identity and self-efficacy and results were analysed via a cluster

12 analysis. Results showed three athlete profiles: (a) athlete students indicating a sport

13 prioritisation; (b) dual career athletes showing an equal balance between vocational career

14 and sporting career; and (c) student athletes showing an education or vocation prioritisation.

15 The results extend the current literature that understands dual career athletes as a

16 heterogeneous group and establishes identity and self-efficacy as important factors in dual

17 career pathways. This understanding also enables practitioners to take an individualistic

18 approach to supporting dual career athletes.

20 athletic lifespan 
Typologies of Dual Career in Sport: A Cluster Analysis of Identity and Self-efficacy The pursuit of a sporting career alongside education or vocational career development (i.e., a dual career) commonly originates during adolescence and early adulthood when aspiring sports performers combine their sporting pursuits with compulsory education (Wylleman et al., 2013). This phase overlaps with formative stages of the individual's physical, psychological, social, and financial development (see holistic athlete career model, Wylleman et al., 2013), and establishing a sense of personal identity (Petitpas \& France, 2010). Engaging in activities such as career exploration and developing a career identity (i.e., the extent to which a person associates their core self with their role relating to work, distinct from their sporting career) has been recognized as an important task in effective career development (Praskova et al., 2015). Vocational career development is recognized as a lifelong process which an individual engages with to understand their occupational motivations, interests, and capabilities (Vondracek et al., 2019). Through this process of exploration and commitment to a vocational role, the individual develops a career identity (Praskova et al., 2015).

Similarly, athletic identity is understood as the "degree to which an individual identifies with the role of an athlete" (Brewer et al., 1993, p. 237). While athletes with a strong athletic identity are generally considered to hold the best chance of athletic success (Carless \& Douglas, 2013), the exclusive commitment to sport, or identity foreclosure (Brewer \& Petitpas, 2017), has been associated with poor adjustment to life after sport, mental health issues (Schinke et al., 2018), and athletic burnout (Goodger et al., 2007), particularly when the transition out of sport is abrupt (i.e., due to a career ending injury; Park et al., 2013; Ronkainen et al., 2016). A dual career has been recognized as, amongst other benefits, protecting against the negative consequences of a one-sided or foreclosed identity (see Aquilina, 2013; Petitpas \& France, 2010). While the benefits of dual career have been 
1 evidenced, the management of two time-consuming pursuits (e.g., sport and education)

2 requires the individual to overcome significant challenges (e.g., adapting to new

3 environments, time management and prioritisation of demands; Brown et al., 2015; Harrison

4 et al., 2020). Therefore, it follows that understanding and enabling the concurrent

5 development of two careers is of vital importance to research and practice.

$6 \quad$ Further to the impact of identity, self-efficacy (i.e., a person's belief in their own

7 ability to produce a specific outcome; Bandura, 2006) in relation to career tasks can increase

8 the likelihood of positive career development behaviours such as career exploration, career

9 decision making, goal setting, motivation towards goals, and performance (Betz, 2001). This

10 complex interaction of exploration, self-efficacy, motivation, and identity enables career

11 development. To provide context, an individual might perform well in a competition, this performance will provide them with information about their ability and impact their confidence in relation to this task. Their confidence then, in turn, impacts upon how they set

14 future goals regarding their career, the motivation they commit towards these goals, and their 15 level of commitment towards their role, which, in a reciprocal nature, impacts upon future 16 performance. This multifaceted interaction becomes yet more complex when considering the multiple career development that characterizes a dual career. To understand the interaction this study refers to the model of multiple dimensions of identity (Jones \& McEwen, 2000), which establishes that different identities can be perceived as closer or further from the 20 individual's core sense of self (i.e., who they see themselves to be). With this in mind, the athletic and vocational career roles are considered to be particularly salient for dual career athletes and are the focus of this investigation.

Previous research has suggested a negative association between athletic identity and aspects of career development, such as career maturity (Houle \& Kluck, 2015; Linnemeyer \& 
1 athletes also reported sacrificing their educational success for sporting success (Cosh \&

2 Tully, 2014). Whereas, further research has shown a positive association between athletic

3 identity and student identity (Poux \& Fry, 2015; Yukhymenko-lescroart, 2014). In fact, the

4 research also reports individuals sacrificing their sporting goals in favour of educational or

5 vocational goals because it was considered unlikely for them to reach the top-level of sport

6 and/or to financially sustain themselves through a sporting career (Gledhill \& Harwood,

7 2015). One explanation for the varying interactions between athletic and career identity and

8 the impact this has on athletic and vocational career development is to recognise the different

9 approaches to a dual career.

10 A growing body of research is emerging that distinguished dual career athletes as a

11 heterogeneous group, with distinct profiles and characteristics. Three dual career motivational

12 patterns have been identified in high school student athletes (Aunola et al., 2018) and youth

13 athletes (Chamorro et al., 2016). Both studies suggested: a dual or balanced motivation

14 pattern, characterized by high value placed on both education, sport, and life; a low academic

15 motivation pattern, characterized by a high value placed on sport but a low value on

16 education or life; and a (relatively) low sport motivated pattern characterized by a lower

17 value placed on sport than on education or life. These three motivational profiles were also

18 seen with similar findings from latent profile analysis of university student athletes (Healy et

19 al., 2016). Furthermore, research shows that differences in motivation can be distinguished by

20 observed variables (i.e., gender, competition level, type of sport, educational area, and year of

21 attendance; Lupo et al., 2015; Lupo et al., 2017).

Further qualitative research investigates the dual career experience and the

23 prioritisation of the two careers. In a study of elite athletes, three pathways were identified,

24 two of which involved a dual career: (a) convergent, in which sport is prioritized over an

25 alternative education; and (b) parallel, in which sport and higher education are equally 
1 prioritized (Pallarés et al., 2011). These pathways were later expanded through an

2 investigation of dual career experiences across the athletic lifespan, including school aged

3 athletes, university student athletes, and athletes in a vocation (Cartigny et al., 2020) which

4 suggested: (a) educational/vocational pathway (i.e., a prioritisation of the vocational career),

5 (b) a parallel dual career pathway (i.e., an equal focus on athletic and vocational career), and

6 (c) a sporting pathway (i.e., a prioritisation of the athletic career). Furthermore, a narrative

7 analysis of young athletes' prospective career futures presents three similar career

8 construction styles (Ryba et al., 2017).

In terms of identity, Stambulova et al. (2015), following an investigation of high

10 school student athletes, suggested that the approaches to a dual career can be viewed as a

11 spectrum from prioritizing sport (and higher visibility of athletic identity) at one end to prioritizing studies (and higher visibility of student identity) at the other end. However, the profile patterns of athletic and vocational career identity have not yet been explored in the literature. In addition, the self-efficacy in relation to athletic tasks and vocational career tasks are also yet to be explored within the literature. Based on the aforementioned understanding of career development, it is considered that further investigation of the identity and selfefficacy patterns of dual career athlete could benefit the research understanding of multiple career development.

The aim of the current study is to explore the patterns of identity and self-efficacy in

20 dual career athletes. From previous research (Aunola et al., 2018; Cartigny et al., 2020;

21 Chamorro et al., 2016; Healy et al., 2016; Stambulova et al., 2015), it can be hypothesised that individuals within each pathway will show a different pattern of athletic and career identity and self-efficacy. More specifically, individuals within a parallel dual career pathway

24 are likely to indicate equal prioritisation between the two identities and self-efficacy; individuals within a vocational pathway are predicted to indicate a stronger inclination 
1 towards their educational or vocational career identity and self-efficacy; and finally,

2 individuals within a sporting pathway are predicted to indicate a stronger athletic identity and

3 self-efficacy in comparison to their educational or vocational identities and self-efficacy.

\section{Methods}

\section{Participants}

6

A sample of 116 dual career athletes volunteered to take part in the current study. An inclusion criterion of currently competing at the national or international level in sport was applied to participants because it was considered to represent a meaningful commitment to a sporting career. Participants' responses were excluded if they had not competed above a regional level, had not combined sport alongside an education or vocation, or had been educated outside of the UK system. Based on these criteria, five participants were removed before analysis. The final sample consisted of 69 female and 42 male participants, with a mean age of 22 years (range 16 - 37 years). The participants represent 42 different sports, including athletics, football, cricket, and rugby. From the 111 participants, 7 dual career athletes had reached an Olympic level, 55 participants had competed at a senior national or international level and the remaining 49 had competed at a junior national or international level. All participants had combined sport with either school $(n=64)$, higher or further education $(n=99)$ or a vocation, occupation or business $(n=18)$, including some participants $(n=9)$ who had combined their sport with all three during their athletic lifespan.

\section{Measures}

To address the purpose of this study, the measures used in this study were selected to investigate aspects of career identity (measured through the Utrecht-Management of Identity Commitments Scale and the academic subscale of the Athletic and Academic Identity Scale), athletic identity (measured via the Athletic Identity Measure Scale and the athletic subscale 
1 of the Athletic and Academic Identity Scale) and self-efficacy (measured through General

2 Self-Efficacy Scale).

The Utrecht-Management of Identity Commitments Scale (ICS; Crocetti et al., 2008)

assesses several aspects of career identity, via the three subscales: identification with commitment (five items), exploration in depth (five items), and reconsideration of commitment (three items). All items are rated on a 5-point Likert scale ranging from 1 (completely untrue) to 5 (completely true). A sum of the item scores were calculated, where higher scores yield greater identification with the career role. Items were adjusted to be applicable to an educational or vocational domain (i.e., "My education gives me selfconfidence" was adjusted to "My education / vocation gives me self-confidence"). In the current sample, the reconsideration of commitment subscale ( 3 items) showed poor internal consistency $(\alpha=0.69)$ and was therefore removed. The remaining 10 items showed a Cronbach's alpha score of $\alpha=0.82(\alpha=0.79$ for identification with commitment subscale and $\alpha=0.81$ for exploration in depth subscale).

The Athletic Identity Measure Scale (AIMS; Brewer et al., 1993) is a 10-item measure designed to evaluate the strength and exclusivity of the athletic role. Responses are given on a 7-point Likert scale ranging from 1 (strongly disagree) to 7 (strongly agree). A sum of the item scores were calculated, where higher scores yield greater identification with the athletic role. There is debate regarding the factor and item structure of the measure (see Visek et al., 2008). Therefore, the internal consistency was re-tested with the current sample. The 10 -item measure showed a high Cronbach's alpha coefficient $(\alpha=0.85)$. Hence the unidimensional version of AIMS is used in the current study.

The Athletic and Academic Identity Scale (AAIS; Yukhymenko-Lescroart, 2014) is an 11-item questionnaire that assesses the academic and athletic identity of student athletes. Respondents are asked to rate characteristics or qualities such as "doing well in school" on a 
1 scale of 1-6, with a 1 indicating that the item is "not central to my sense of self" and 6

2 indicating that it is "very central to my sense of self". The scale consists of two subscales, the

3 first containing 5 items related to the student role and the second containing 6 characteristics

4 related to the athletic role. A sum of the items scores is calculated for each subscale

5 separately, where higher scores yield greater identification with the student and athletic role,

6 respectively. The student subscale was adapted to include vocational aspects of an

7 individual's career (i.e., the item "Doing well in school" was adjusted to "Doing well in

8 school / work"). Both subscales showed a strong internal consistency with an Omega

9 coefficient score of 0.90 and 0.94 (respectively).

10 The General Self-Efficacy Scale (Sherer \& Adams, 1983) was used to assess self-

11 efficacy. The scale consists of 11 items, all rated on a 5-point Likert scale ranging from 1

12 (strongly disagree) to 5 (strongly agree). A sum of the item scores were calculated, where

13 higher scores indicate that the individual holds a stronger self-belief that they will be able to

14 achieve their goals. Bandura (2006) recommended that measures of self-efficacy should be

15 tailored to the domain of functioning of interest, therefore, in this study the scale was used

16 twice within the survey, once for the vocational or educational domains and once for the

17 athletic domain. The scale showed high internal consistency with the current sample for

18 career self-efficacy $(\alpha=0.83)$ and for athletic self-efficacy $(\alpha=0.86)$.

\section{Data Collection}

The procedure for this study received institutional ethical clearance before participant recruitment commenced. The aim of the participant recruitment process was to target dual career athletes with experience of combining sport with an education or vocation. As an incentive to take part, participants were offered either module credits (only available at one university) or were entered into a prize draw for taking part. The survey questions were completed online by all participants and included questions to establish the demographic 
1 characteristics of the participant (e.g., individual's age, gender) and their education,

2 vocational, and sporting experiences.

\section{Data Analysis}

The data analysis consisted of a preliminary analysis of the variables (performed in

5 IBM SPSS statistics package version 24.0), a principle component analysis (PCA), and a

6 cluster analysis (both performed in R version 3.0.1). In accordance with the

7 recommendations, a sample size of 111 was considered as sufficient for PCA with nine variables (Bandalos \& Boehm-Kaufman, 2009). The current study used a two steps clustering method, as recommended by several authors (Gore, 2000; Hair et al., 2013), which combines

10 hierarchical and non-hierarchical clustering methods and hence provides an increased

11 confidence in the stability of the cluster solution (Hair et al., 2013; Jain, 2010). Nine

12 clustering variables were selected on the basis of their considered contribution to

13 characterizing the dual career experience: age, sporting level, educational level, career

14 identity (ICS and AAIS - academic subscale), career self-efficacy, athletic identity (AIMS

15 and AAIS - athletic subscale), and athletic self-efficacy. The non-metric variables were

16 measured with 7 ordered levels (for sporting level), and 8 ordered levels (for educational

17 level). The PCA method used by the R package that we employed is based on singular value

18 decomposition (SVD) is generally considered accurate and suitable for ordinal variables

19 (Lombardo \& Beh, 2010). These variables were standardized by scaling to 0,1 to create data

20 that was comparable between the varying scales. The cluster groups were then examined for

21 their difference on the variables and labelled according to the participants that they best represented.

\section{Results}

\section{Preliminary Analysis}


After preliminary analysis, all variables showed normal distributions, with the exception of athletic identity (AIMS and AAIS - athletic subscale) showing a slight skew towards higher values. Since the study sample is an athlete population, this skew towards a

higher athletic identity is to be expected. A correlation matrix (see Table 1) was conducted to assess the factorability of all variables: age, sporting level, educational level, career identity (ICS and AAIS - academic subscale), career self-efficacy, athletic identity (AIMS and AAIS - athletic subscale), and athletic self-efficacy. The internal correlation of the career variables was considered to be strong. Similarly, the athletic identity (AIMS) was strongly internally correlated to athletic self-efficacy and AAIS - athletic subscale.

\section{Principle Component Analysis}

A PCA was conducted to establish the correlation between the variables and the validity in using all the variables selected. The PCA indicated three components which collectively explained $58.8 \%$ of the variance. Table 2 presents the rotated factor loadings of each variable on the three components (with a cut off level of 0.30 , representing a significant contribution of that variable to the component). This mapping forms the basis for the cluster analysis, where participants and clusters are plotted along the first two components.

\section{Cluster Analysis}

A hierarchical cluster analysis was undertaken to identify the number of clusters that are most appropriate. From considering the dendrogram and agglomeration schedule, a threecluster solution was considered to produce the optimal cluster size for detailed groups whilst maintaining meaningful differences between the clusters. The k-means analysis was then used to separate all participants into three clusters (see Figure 1), which are described in detail below and summarized in Table 3. To further illustrate the characteristics of the clusters, box plots of all the input variables are shown in Figure 2. 
Cluster $1(n=45)$ contains the youngest participants with a median age of 19 years (interquartile range, IQR 19-21). The group contained undergraduate 1st year students.

Sporting level scores suggest that cluster 1, were talented junior athletes that have transitioned to the senior level. This group of participants had the highest, compared to the other two clusters, athletic identity (AIMS) median score (58; IQR 55-61). In comparison, this cluster showed lower career identity (ICS) median score (48; IQR 47-51). The AAIS subscales showed a similar pattern, with cluster 1 showing the highest, of the three clusters, athletic subscale scores (median 38; IQR 15-42) and intermediate academic subscale scores (median 27; IQR 6-30). Furthermore, this group showed stronger self-believe in their athletic abilities than any other cluster (athletic self-efficacy: median 34; IQR 32-36) and stronger self-believe in their career abilities, than cluster 2 (career self-efficacy: median 41; IQR 4045). Based on these scores, it appears that cluster 1 represents an athlete-student (i.e., a prioritisation of the athletic career).

Cluster 2 contains participants $(\mathrm{n}=40)$ with a median age of 20 years (IQR 19-22), representing undergraduate students, who are talented junior athletes. This group appeared to contain individuals with a balanced dual career (i.e., an equal focus on athletic and vocational career) based on similar athletic identity (AIMS; median 46; IQR 45-49) and career identity (ICS) median scores (median 50; IQR 43-66). Cluster 2, scored the lowest, of the three clusters, on both the AAIS subscales (athletic subscale, median 31; academic subscale, median 20). This could suggest this cluster holds an identity more central to their core self than their athletic or career identities. However, this group had both the lowest, compared to other clusters, athletic self-efficacy (median 29; IQR 27-31) and career self-efficacy median scores (median 40; IQR 37-41).

Cluster $3(n=29)$ contains the oldest participants with a median age of 27 years (IQR 25-31 years). This group represents undergraduate 3rd year or postgraduate students or those 
1 who are working. This cluster showed the highest median sporting level and were likely to be

2 talented young athletes who reached the senior national level. Cluster 3 appeared to contain

3 student-athletes who prioritise their education or vocational career over their athletic career

4 based on the highest career identity (ICS) scores (median 51; IQR 56-64) and the lowest

5 athletic identity (AIMS) scores (median 48; IQR 38-53), compare to the other clusters. The

6 AAIS subscales showed a similar pattern, with cluster 3 showing the highest, of the three

7 clusters, academic subscale scores (median 28, IQR 18-35) and intermediate athletic subscale

8 scores (median 35; IQR 19-38). This group also had a strong belief in their abilities in

9 relation to their vocation or education with the highest career self-efficacy scores (median 46;

10 IQR 43-49) compared to the other clusters. In comparison, cluster 3 showed a weaker belief

11 in their abilities related to their athletic career (athletic self-efficacy: median 31; IQR 29-34).

\section{Discussion}

The current study investigated the prediction, from previous research (Aunola et al., 2018; Cartigny et al., 2020; Chamorro et al., 2016; Healy et al., 2016; Lupo et al., 2015;

Stambulova et al., 2015), that individuals within different dual career pathways will show different patterns of identity and self-efficacy in relation to their dual roles in sport and a vocational career. Via a cluster analysis, this prediction was maintained and identified three dual career profiles: (a) athlete-students who indicate a sporting pathway and an increased focus towards their sporting career; (b) dual career athletes who indicate a parallel dual career pathway and equal focus between their sporting and educational or vocational careers and; (c) student athletes who indicate an educational/vocational pathway and increased focus on their educational or vocational careers. The results of this study extend the evidence to support the understanding of dual career athletes as a heterogenous group that has been proposed by previous research (Aunola et al., 2018; Chamorro et al., 2016; Healy et al., 2016, Ryba et al., 
1 athletes. The current findings not only provide evidence for the three dual career pathways

2 put forward in the 'mind the gap' theory (Cartigny et al., 2020), it also extends the theory by

3 illustrating that the psychological constructs of identity and self-efficacy are distinct between

4 the pathways.

The results present an explanation for the inconsistent findings of previous studies which investigated athletic identity and aspects of career development. The inverse relationship between athletic identity and career development (Cabrita et al., 2014; Houle \& Kluck, 2015; Linnemeyer \& Brown, 2010) would be consistent with the athlete-student or cluster 1 of this study. Whereas, research which has shown no relationship between athletic identity and vocational development (Martens \& Cox, 2000; Praskova et al., 2015) could be understood as the balanced dual career athlete or cluster 2 within this study. In previous research, dual career athletes' motivation towards their sports, academics and careers were distinguished through observational variables (e.g., sporting level, gender, and year of attendance in education; Lupo et al., 2017). However, the impact of gender in distinguishing dual career motivations has shown to differ based on the national approach to dual career (i.e., the opportunities for female athletes in professional sports and dual career programs; Lupo et al., 2015). In reference to identity, female athlete participants have shown to hold a more student-oriented identity (Brustio et al., 2020). In the present study, gender was not found differ between the clusters. It is therefore, suggested that this is an influence of the national context of the UK.

This study is considered to advance the current research knowledge because it provides evidence for identity and self-efficacy as factors associated with different dual career profiles, where previously only motivational profiles have been considered in this way. This study shows that self-efficacy plays a significant role in the prioritisation of the careers (sport and vocation) and, in general, the self-efficacy of the individual reflected their identity 
1 (i.e., an individual with a strong athletic identity would also show a strong athletic self-

2 efficacy). This study uses a diverse participant sample (i.e., dual career athletes in school,

3 university and in employment), and, therefore, extends the understanding of dual career

4 pathways over the lifespan, as opposed to a previous focus on one cohort of high school

5 athletes, youth athletes, or higher education athletes.

6 The current study is based on the model of multiple dimensions of identity (Jones \&

7 McEwen, 2000) which states that every individual possesses multiple identities of differing

8 salience to their core self. This investigation focused on, what is presumed through the

9 literature to be, the two most salient roles to a dual career individual (their athletic and their

10 vocational career roles). However, the current study did not consider the interaction and

11 impact of the entirety of the individual's roles (e.g., their role as friend, sibling, parent, etc.).

12 The current approach also focused on a cross-sectional understanding of dual career

13 individual's career and athletic roles. As understood in this study, identity is a life-long

14 process that is susceptible to change (Vondracek et al., 2019). Therefore, understanding the

15 stability of the career and sporting roles over time within each pathway is of vital importance

16 for future research. Finally, this study was conducted in the UK context, therefore, the

17 generalisability of the research findings is limited, without further investigation, to more

18 diverse cultural contexts.

The research area could still benefit from a more detailed understanding of several key areas: a) the stability of identity, self-efficacy, and motivation towards dual career goals over

21 key transitions; b) an examination of identity, self-efficacy, and motivation towards dual career goals from a longitudinal perspective; and c) an understanding of identity, selfefficacy, and motivation towards dual career goals from different sports and different dual career environments. The impact of additional roles such as these could be a fruitful line of

25 inquiry, particularly as these roles adapt or are introduced over time (e.g., becoming a 
1 parent). The results produced by the current study also present some considerations for

2 conducting research with a dual career population. Explicitly, the dual career typologies

3 showed distinct characteristics and are suggested to pursue dual careers in different ways.

4 Future research must consider the type of dual career experience the research question is

5 directed towards and ensure that the sample is representative of this group.

6 The understanding of dual career athletes through three profiles of individuals,

7 presents some important considerations for those practicing within the dual career area. The

8 current study calls into question the value of supporting dual career athletes with distinct

9 characteristics through the same support mechanisms. Practitioners should consider that each

10 dual career type and each pathway requires a different approach to support and requires

11 different preparations for the individual's future. To expand, the athlete-student shows a

12 higher athletic identity than career identity and are, therefore, likely to prioritise their sporting

13 role to the detriment of their career goals. As a result, these individuals are likely to require

14 support to prepare in advance for their post-sport career (e.g., part-time study and distance

15 learning techniques), but are likely to require the most support in their transition out of sport

16 (e.g., support with a changing identity and starting a new career). The parallel dual career

17 pathway, exhibited by cluster 2, enables dual career athletes to achieve both career and

18 sporting goals, however, this pathway requires substantial amounts of support and flexibility

19 from sport and education/vocation organisations (see Henry, 2013). Finally, cluster 3

20 suggests a reduced commitment to, or dropout from, competitive sport. This pathway is

21 problematic for sport because it signifies a large talent participation loss from sport. It is

22 important, therefore, for practitioners and sporting organisations to understand the typologies

23 of dual career athlete that they support and how best to support their career decisions,

24 including the continuation of sport. 


\section{Conclusion}

In summary, the current study presents identity and self-efficacy, alongside motivation

3 (which has been presented by previous research; Aunola et al., 2018; Chamorro et al., 2016;

4 Healy et al., 2016, Lupo et al., 2016), as factors that can distinguish the emphasis individuals

5 place on their sporting and vocational careers within a dual career. In particular, athlete

6 students are characterised by sport prioritisation, parallel dual career athletes are

7 characterised by an equal focus on sporting and vocational careers, and student athletes that is

8 characterised by a vocational career prioritisation. In doing this, the results also extends the

9 current literature that understands dual career athletes as a heterogeneous group and

10 encourages practitioners to take an individualistic approach to supporting dual career athletes.

11 Acknowledgements

12 Declarations of interest: none. 
References

2 Aquilina, D. (2013). A study of the relationship between elite athletes' educational development and sporting performance. International Journal of the History of Sport, 30(4), 374-392. doi:10.1080/09523367.2013.765723

Aunola, K., Selänne, A., Selänne, H., \& Ryba, T. V. (2018). The role of adolescent athletes' task value patterns in their educational and athletic career aspirations. Learning and Individual Differences, 63, 34-43. doi:10.1016/j.lindif.2018.03.004

Bandalos, D. L., \& Boehm-Kaufman, M. R. (2009). Four common misconceptions in exploratory factor analysis. In C. E. Lance \& R. J. Vandenberg (Eds.), Statistical and methodological myths and urban legends (pp. 61-87). Routledge.

Bandura, A. (2006). Guide to creating self-efficacy scales. In F. Pajares \& T. Urdan (Eds.), Self-efficacy beliefs of adolescents (pp. 307-337). Information Age Publishing.

Betz, N. (2001). Career self-efficacy. In F. Leong \& A. Barak (Eds.), Contemporary models in vocational psychology (pp. 55-78). Lawrence Erlbaum Associates.

Brewer, B. W. \& Petitpas, A. J. (2017). Athletic identity foreclosure. Current Opinion in Psychology, 16, 118-122. https://doi.org/10.1016/j.copsyc.2017.05.004

Brewer, B. W., Van Raalte, J. L., \& Linder, D. E. (1993). Athletic identity: Hercules' muscles or Achilles' heel? International Journal of Sport Psychology, 24(2), 237-254.

Brown, D. J., Fletcher, D., Henry, I., Borrie, A., Emmett, J., Buzza, A., \& Wombwell, S. (2015). A British university case study of the transitional experiences of studentathletes. Psychology of Sport and Exercise, 21, 78-90. https://doi.org/10.1016/j.psychsport.2015.04.002 
1 Brustio P. R., Rainoldi, A., Mosso, C. O., López de Subijana, C. \& Lupo, C. (2020). Actual and wished supports to promote a successful dual career according to Italian studentathletes' point of view. Sport Sciences for Health. doi.org/10.1007/s11332-02000635-5.

Cabrita, T. M., Rosado, A. B., Leite, T. O., Serpa, S. O., \& Sousa, P. M. (2014) The relationship between athletic identity and career decisions in athletes. Journal of Applied Sport Psychology, 26(4), 471-481. doi:10.1080/10413200.2014.931312

Carless, D., \& Douglas, K. (2013). Living, resisting, and playing the part of athlete: Narrative tensions in elite sport. Psychology of Sport and Exercise, 14(5), 701-708. doi:10.1016/j.psychsport.2013.05.003

Cartigny, E., Fletcher, D., Coupland, C., \& Taylor, G. (2020). Mind the gap: A grounded theory of dual career pathways in sport. Journal of Applied Sport Psychology. Advance online publication. doi:10.1080/10413200.2019.1654559

Chamorro, J., Torregrosa, M., Sánchez Oliva, D., García Calvo, T., \& León, B. (2016). Future achievements, passion and motivation in the transition from junior-to-senior sport in Spanish young elite soccer players. The Spanish Journal of Psychology, 19, E69. doi:10.1017/sjp.2016.71

Cosh, S. \& Tully, P. J. (2014). "All I have to do is pass": A discursive analysis of student athletes' talk about prioritising sport to the detriment of education to overcome stressors encountered in combining elite sport and tertiary education. Psychology of Sport and Exercise, 15(2), 180-189. doi:10.1016/j.psychsport.2013.10.015

Crocetti, E., Rubini, M., \& Meeus, W. (2008). Capturing the dynamics of identity formation in various ethnic groups: Development and validation of a three-dimensional model. Journal of Adolescence, 31, 207-222. doi:10.1016/j.adolescence.2007.09.002 
1 Gledhill, A. \& Harwood, C. (2015). A holistic perspective on career development in UK female soccer players: A negative case analysis. Psychology of Sport and Exercise, 21, 65-77. doi:10.1016/j.psychsport.2015.04.003

Goodger, K., Gorely, T., Lavalle, D., \& Harwood, C. (2007). Burnout in sport: A systematic review. The Sport Psychologist, 21(2), 125-149. https://doi.org/10.1123/tsp.21.2.127

Gore, P. A. (2000). Cluster analysis. In H. E. Tinsley \& S. D. Brown (Eds.), Handbook of applied multivariate statistics and mathematical modelling (pp. 297-321). Academic Press.

Hair, J. F., Black, W. C., Babin, B. J., \& Anderson, R. E. (2013). Cluster analysis. In J. F. Hair, W. C., Black, B. J. Babin, \& R. E. Anderson (Eds), Multivariate data analysis: Pearson new international edition (pp. 415-475). Pearson Education Limited.

Harrison, G. E., Vickers, E., Fletcher, D., \& Taylor, G. (2020). Elite female soccer players' dual career plans and the demands they encounter. Journal of Applied Sport Psychology. Advance online publication. https://doi.org/10.1080/10413200.2020.1716871

Healy, L. C., Ntoumanis, N., \& Duda, J. L. (2016). Goal motives and multiple-goal striving in sport and academia: A person-centered investigation of goal motives and inter-goal relations. Journal of Science and Medicine in Sport, 19(12), 1010-1014. doi:10.1016/j.jsams.2016.03.001

Henry, I. (2013). Athlete development, athlete rights and athlete welfare: a European Union perspective. The International Journal of the History of Sport, 30(4), 356-373. doi:10.1080/09523367.2013.765721

Houle J, L. W. \& Kluck, A. S. (2015). An examination of the relationship between athletic identity and career maturity in student-athletes. Journal of Clinical Sport Psychology, 9(1), 24-40. doi:10.1123/jcsp.2014-0027 
1 Jain, A. K. (2010). Data clustering: 50 years beyond K-means. Pattern Recognition Letters, 31(8), 651-666. doi:10.1016/j.patrec.2009.09.011

3

Jones, S. R., \& McEwen, M. K. (2000). A conceptual model of multiple dimensions of identity. Journal of College Student Development, 41(4), 405-414.

Linnemeyer, R. M. \& Brown, C. (2010). Career maturity and foreclosure in student athletes, fine arts students, and general college students. Journal of Career Development, 37, 616-634. doi:10.1177/0894845309357049

Lombardo, R. \& Beh, E. J. (2010). Simple and multiple correspondence analysis for ordinal scale variables using orthogonal polynomials. Journal of Applied Statistics, 37(12), 2101-2116. doi:10.1080/02664760903247692

Lupo, C., Guidotti, F., Goncalves, C., Moreira, L., Topic, M. D., Bellardini, H., Tonkonogi, M., Colin, A., \& Capranica, L. (2015). Motivation towards dual career of European student-athletes. European Journal of Sport Science, 15(2), 151-160. doi:10.1080/17461391.2014.940557

Lupo C., Mosso C. O., Guidotti F., Cugliari G., Pizzigalli L., \& Rainoldi A. (2017). Motivation toward dual-career of Italian student-athletes enrolled in different university paths. Sport Sciences for Health. 13(3), 485-494.

Martens, M. P. \& Cox, R. H. (2000). Career development in college varsity athletes. Journal of College Student Development, 41(2), 172-180.

Melendez, M. C. (2009). Psychosocial influences on college adjustment in division I studentathletes: The role of athletic identity. Journal of College Student Retention: Research, Theory and Practice, 11(3), 345-361. doi:10.2190/CS.11.3.c 
1 Pallarés, S., Azócar, F., Torregrosa, M., Selva, C., \& Ramis, Y. (2011). Modelos de trayectoria deportiva en waterpolo y su implicación en la transición hacia una carrera profesional alternativa.(Athletic Career Models in Water Polo and their Involvement in the Transition to an Alternative Career). Cultura, Ciencia y Deporte, 6(17), 93-103.

Park, S., Lavallee, D., \& Tod, D. (2013). Athletes' career transition out of sport: a systematic review. International Review of Sport and Exercise Psychology, 6(1), 22-53. doi:10.1080/1750984X.2012.687053

Petitpas, A. J. \& France, T. (2010). Identity foreclosure in sport. In S. J. Hanrahan \& M. B. Anderson (Eds.), Routledge handbook of applied sport psychology: A comprehensive guide for students and practitioners (pp. 282-291). Routledge.

Poux, K. N. \& Fry, M. D. (2015). Athletes' perceptions of their team motivational climate, career exploration and engagement, and athletic identity. Journal of Clinical Sport Psychology, 9(4), 360-372.

Praskova, A., Creed, P. A., \& Hood, M. (2015). Career identity and the complex mediating relationships between career preparatory actions and career progress markers. Journal of Vocational Behavior, 87, 145-153.

Ronkainen, N. J., Kavoura, A., \& Ryba, T. V. (2016). A meta-study of athletic identity research in sport psychology: Current status and future directions. International Review of Sport and Exercise Psychology, 9(1), 45-64.

Ryba, T. V., Stambulova, N. B., Selänne, H., Aunola, K., \& Nurmi, J. (2017). "Sport has always been first for me" but "all my free time is spent doing homework": Dual career styles in late adolescence. Psychology of Sport and Exercise, 33, 131-140. doi:10.1016/j.psychsport.2017.08.011 
1 Schinke, R. J., Stambulova, N. B., Si, G., \& Moore, Z. (2018). International society of sport psychology position stand: Athletes' mental health, performance, and development. International Journal of Sport and Exercise Psychology, 16(6), 622-639.

Sherer, M., \& Adams, C. H. (1983). Construct validation of the self-efficacy scale. Psychological Reports, 53(3), 899-902. doi:10.2466/pr0.1983.53.3.899

Stambulova, N. B., Engström, C., Franck, A., Linnér, L., \& Lindahl, K. (2015). Searching for an optimal balance: Dual career experiences of Swedish adolescent athletes. Psychology of Sport and Exercise, 21, 4-14. doi:10.1016/j.psychsport.2014.08.009

Visek, A. J., Hurst, J. R., Maxwell, J. P., \& Watson, J. C. (2008). A cross-cultural psychometric evaluation of the Athletic Identity Measurement Scale. Journal of Applied Sport Psychology, 20(4), 473-480. doi:10.1080/10413200802415048

Vondracek, F. W., Lerner, R. M., \& Schulenberg, J. E. (2019). Career development: A lifespan developmental approach. Routledge.

Wylleman, P., Reints, A., \& De Knop, P. (2013). A developmental and holistic perspective on athletic career development. In P. Sotiaradou \& V. De Bosscher (Eds.), Managing high performance sport (pp. 159-182). Routledge.

Yukhymenko-Lescroart, M. A. (2014). Student and athletes? Development of the Academic and Athletic Identity Scale (AAIS). Sport, Exercise, and Performance Psychology, 3(2), 89-101. doi:10.1037/spy0000009 
Table 1

Partial correlation matrix for cluster analysis, between the sporting and career variables, and age.

\begin{tabular}{|c|c|c|c|c|c|c|c|c|c|}
\hline & Age & Sport Level & $\begin{array}{c}\text { Education } \\
\text { Level }\end{array}$ & $\begin{array}{c}\text { Career } \\
\text { Identity } \\
\text { (ICS) }\end{array}$ & $\begin{array}{c}\text { Career } \\
\text { Self- } \\
\text { efficacy }\end{array}$ & $\begin{array}{c}\text { AAIS - } \\
\text { academic } \\
\text { subscale }\end{array}$ & $\begin{array}{l}\text { Athletic } \\
\text { Identity } \\
\text { (AIMS) }\end{array}$ & $\begin{array}{l}\text { Athletic } \\
\text { Self- } \\
\text { efficacy }\end{array}$ & $\begin{array}{l}\text { AAIS - } \\
\text { athletic } \\
\text { subscale }\end{array}$ \\
\hline Standard deviation & 6.52 & 1.66 & 1.50 & 6.86 & 5.49 & 5.25 & 6.67 & 9.97 & 4.29 \\
\hline Sport Level & & - & & & & & & & \\
\hline Education Level & & & - & & 0.24 & & & -0.26 & \\
\hline Career Identity (ICS) & & & & - & 0.34 & 0.25 & & & \\
\hline Career Self-efficacy & & & & & - & 0.23 & & & 0.19 \\
\hline AAIS - athletic subscale & & & & & & & & & - \\
\hline
\end{tabular}

Only Spearman's rho values that were significant to $P<0.05$ are shown 
Table 2

Variance explained and rotated factor loadings of the three principle components.

Significant values with at least 0.3 are shown

\begin{tabular}{lccc}
\hline Variable & PC1 & PC2 & PC3 \\
\hline Percentage variance explained (\%) & 25.0 & 20.5 & 13.3 \\
Age & -0.53 & - & - \\
Sporting level & - & - & -0.60 \\
Educational level & -0.48 & - & - \\
Career identity (ICS) & - & - & 0.52 \\
Career self-efficacy & -0.33 & 0.40 & - \\
AAIS - academic subscale & - & 0.45 & 0.37 \\
AAIS - athletic subscale & - & 0.48 & - \\
Athletic identity (AIMS) & 0.43 & - & - \\
Athletic self-efficacy & - & 0.51 & - \\
\hline
\end{tabular}




\section{Table 3}

Cluster solution and cluster characteristics summary

\begin{tabular}{lll}
\hline Cluster & Label & Median Characteristics \\
\hline & Age 19; $1^{\text {st }}$ year undergraduate student; senior national \\
& athlete; intermediate* career identity scores; highest* \\
& athletic identity scores; intermediate* career self-efficacy \\
& scores; highest* athletic self-efficacy scores. \\
& Age 20; $1^{\text {st }}$ year undergraduate student; junior national \\
& athlete; lowest* career identity scores; intermediate* \\
& athletic identity scores; lowest* career and athletic self- \\
& efficacy scores. \\
& Age $27 ; 3^{\text {rd }}$ year undergraduate student; junior international \\
& athlete; highest* career identity scores; lowest* athletic \\
& identity scores; highest* career self-efficacy scores; \\
& intermediate* athletic self-efficacy scores.
\end{tabular}

\footnotetext{
* compare to other clusters
} 


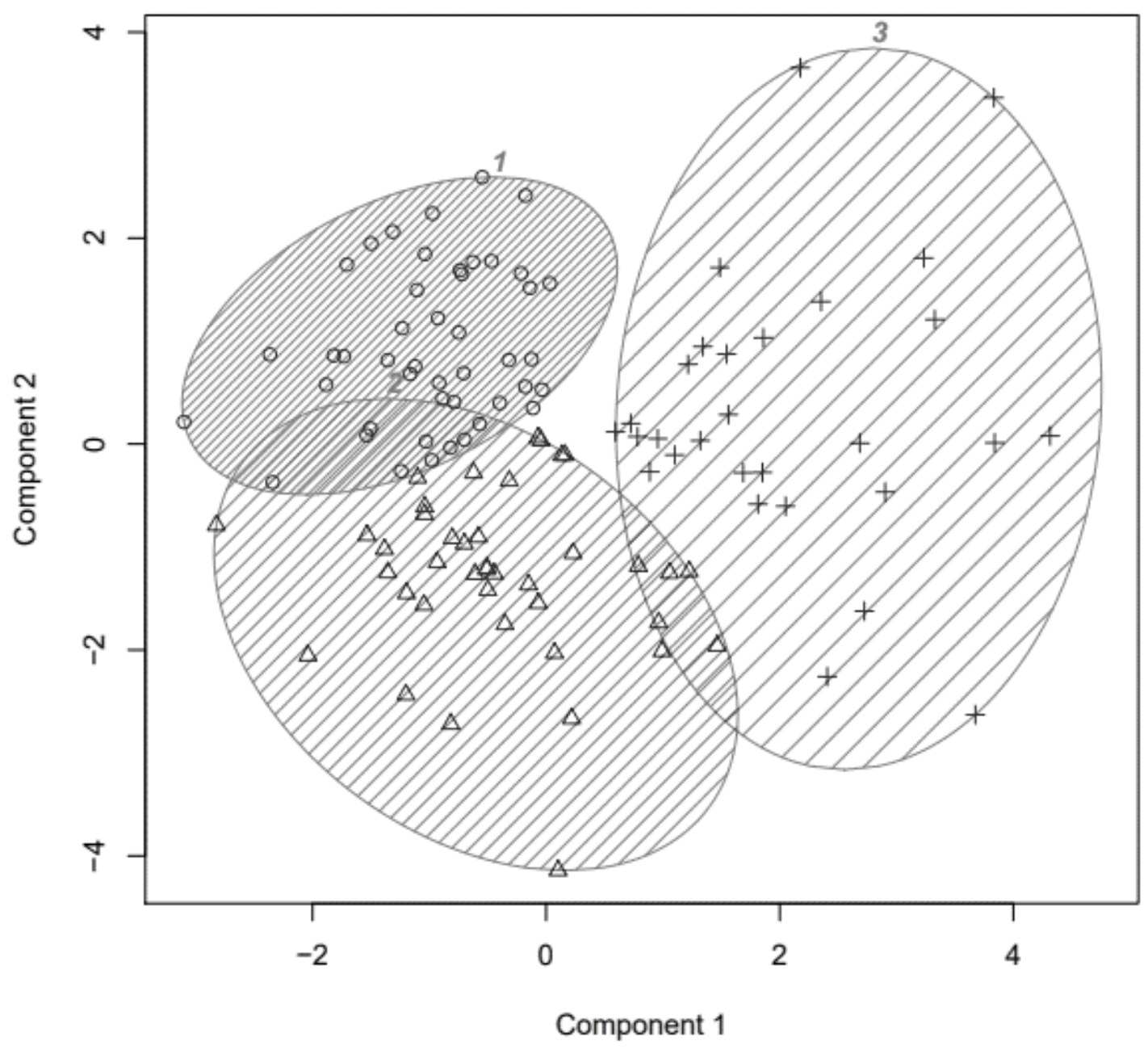

2 Figure 1. K-means cluster solution, based on the two principle components, illustrating three 3 clusters. 


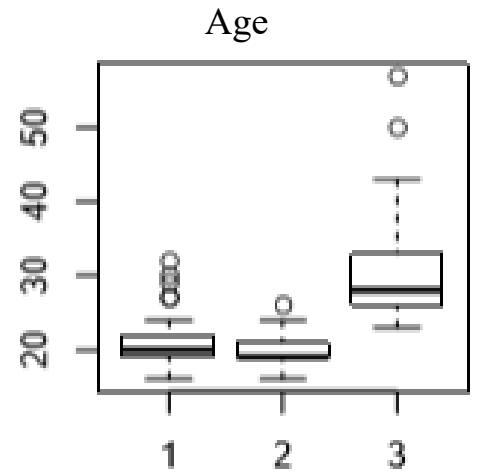

Career Identity (ICS)

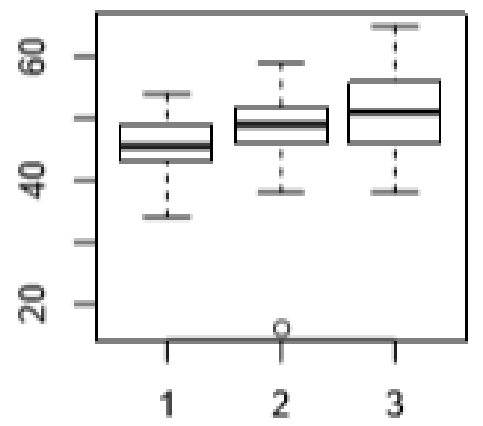

Athletic Identity (AIMS)

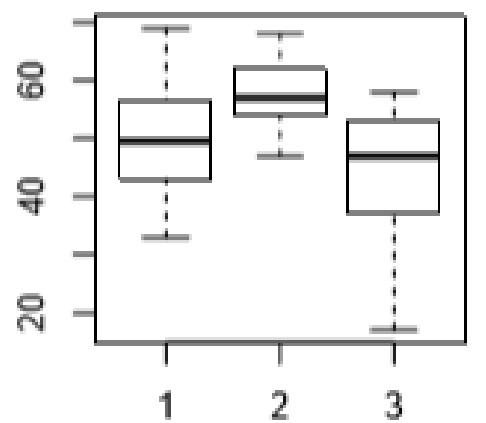

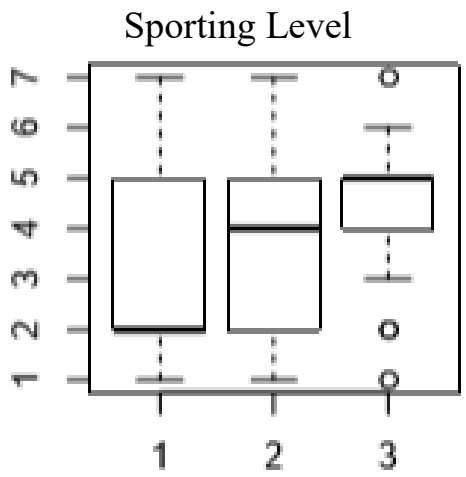

Career Self-efficacy

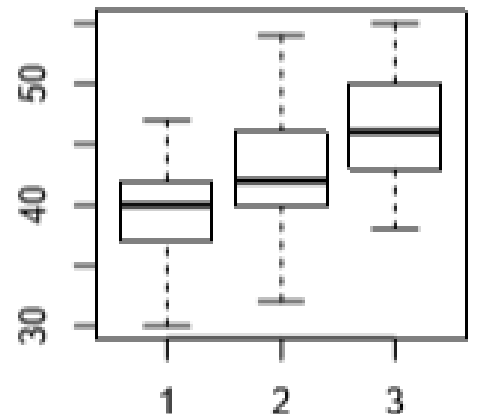

Athletic Self-efficacy

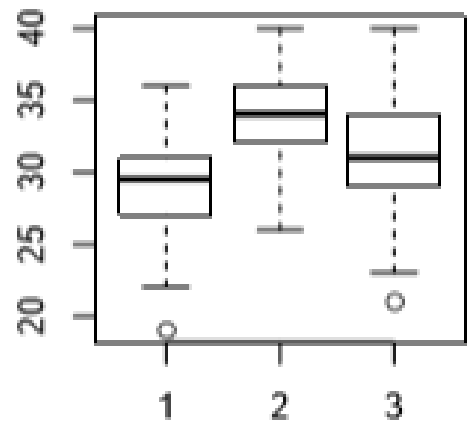

Educational Level

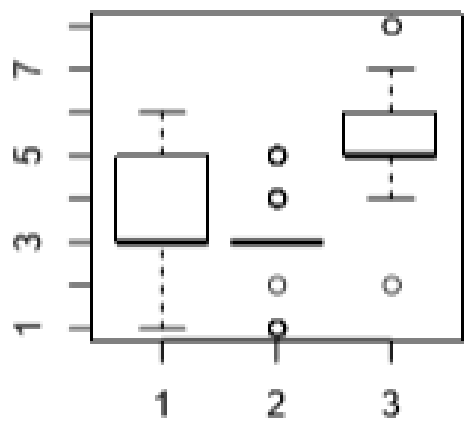

AAIS - academic subscale

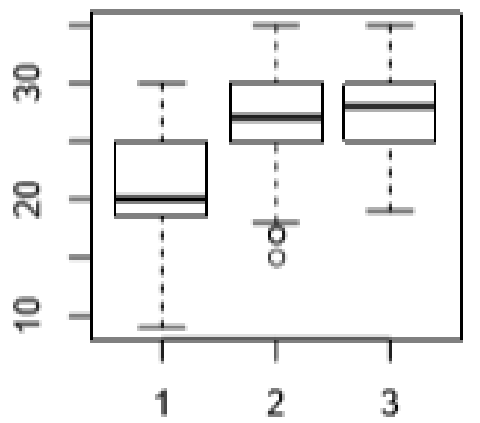

AAIS - athletic subscale

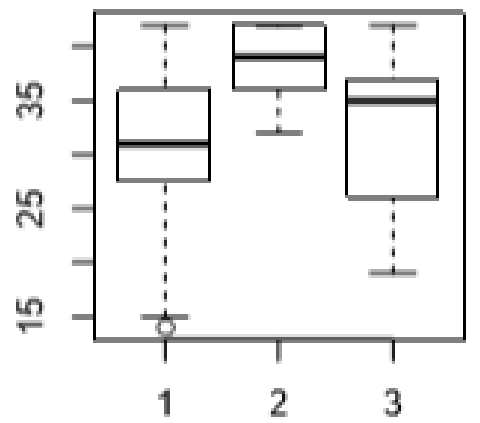

1 Figure 2. Box plots of the scores on the variables entered into the cluster analysis, split by cluster,

2 indicated on $\mathrm{x}$ axis. Outliers are defined as values outside 1.5 times the interquartile range (IQR)

3 above the upper quartile and below the lower quartile ( $>$ Q3 $+1.5 *$ IQR or $<$ Q1 $-1.5^{*}$ IQR). 